\title{
Study of functional outcome of surgical management of proximal humerus fracture by various modalities: a two-year study at a tertiary care hospital
}

\author{
Addanki Vijayanand, Narreddy Jayasomeswar*
}

Department of Orthopaedics, Narayana Medical College and Hospital, Chinthareddypalem, Nellore, Andhra Pradesh, India

Received: 12 December 2019

Accepted: 30 December 2019

\section{*Correspondence:}

Dr. Narreddy Jayasomeswar,

E-mail: sujithbhanu1212@gmail.com

Copyright: () the author(s), publisher and licensee Medip Academy. This is an open-access article distributed under the terms of the Creative Commons Attribution Non-Commercial License, which permits unrestricted non-commercial use, distribution, and reproduction in any medium, provided the original work is properly cited.

\section{ABSTRACT}

Background: Proximal humerus fractures account for nearly 6-10\% and are on a rise. The management of this is controversial and is challenging task. There is a significant heterogeneity among the studies in describing the best surgical procedure in proximal humerus fracture. The objective of the study is to assess and compare the functional outcome with different modalities in fixation of proximal humerus shaft fractures.

Methods: A two-year prospective study was conducted after getting ethical approval at Narayana Medical College on cases admitted with proximal humerus fractures as per the inclusion criteria based on Neer's classification. Radiological evaluation was done, and surgery was performed. Postoperative follow-up was done at 1st, 4th, 8th and 14th week and outcome were evaluated for each case based on Neer's shoulder score.

Results: 30 cases were included with a mean age of 48.2 years. Road traffic injury was common cause of fracture. Of the total 30 cases, 23 cases had excellent results, 4 cases were satisfactory, 2 cases were unsatisfactory, and one case had a failure. The mean scores observed on Neer's score was pain (33.5 units), Function (23.5 units), range of motion (16.55 units) and anatomy (6.9 units).

Conclusions: Clinical evaluation, obtaining proper radiological views, age of the patient and activity holds the key for realistic approach and surgical management of complex humerus fractures. Proper patient selection and thorough knowledge of the anatomy and biomechanical principles are the pre-requisites for a successful surgery and good functional outcome.

Keywords: Neer's score, Humerus fracture, Range of motion, Functional outcome

\section{INTRODUCTION}

Proximal humerus fractures are one of the commonest fractures encountered in an orthopaedic practice. They account for nearly 6-10\% and may be on a rise. They are the third most common osteoporotic fracture after distal radius and vertebra. The distribution of humeral fracture according to age is typical with high velocity trauma being the common cause among young individuals and a simple fall in older individuals because of osteoporosis. ${ }^{1}$ However the management of this is controversial and is challenging task. Majority of these fractures are stable, minimally displaced or nondisplaced and mostly managed by nonoperative techniques like immobilization, splints and casts etc. However, these techniques are associated with complications and disabilities like avascular necrosis, nonunion and malunion. ${ }^{2}$ With increase in the incidence of upper humerus fractures and advances in the techniques of surgery most of the surgeons prefer an operative management than conservative management. The various surgical modalities used are transosseous suture fixation, closed reduction and percutaneous fixation, open 
reduction and internal fixation with conventional plates, locking plate fixation and hemiarthroplasty which have shown to have mixed results. There is a significant heterogeneity among the studies in describing the best surgical procedure in proximal humerus fracture. No single approach is considered the best of standard of care in management of fracture. ${ }^{3}$

The present aim of the study is to study the occurrence, mechanism of injury and displacement of various types of fracture according to Neer's score system. The study aims to assess and compare the functional outcome with different modalities in fixation of proximal humerus shaft fractures.

\section{METHODS}

The present prospective study was conducted in the Department of Orthopaedics for a period of two years from January 2017 to December 2018 at Narayana Medical College a tertiary care hospital in South India. The study protocol was presented before the ethical committee and approved. The entire study was conducted as per the guidelines of the committee. The study participants were informed about the study details and informed written consent was obtained from them. The history of injury of the participants, general condition and any associated soft tissue injury were evaluated. The severity of the injury was assessed to assess local injury and axillary nerve was assessed by examining any anaesthetic patch over lateral aspect of the shoulder.

\section{Inclusion criteria}

All the cases with proximal humerus fractures above 18 years of age and consenting for the study were included. [Neer's classification: grade 2 to Grade 4]. ${ }^{4}$

\section{Exclusion criteria}

Cases with Pathological fractures, with distal neuro vascular deficit, poly trauma patients with injury severity score $>16$, shaft humerus fractures with proximal extension.

Radiological evaluation of all the included cases were done as per the Neer's trauma series which include, AP view of the scapula, lateral "Y" view of the scapula, axillary view and occasionally the velpeau view was taken.

All the routine surgical investigations were done on the included cases and anaesthetic fitness was also evaluated. The modality of the treatment was decided based upon the following factors: Neer's classification [grade 2 to grade 4]; presence of humeral head dislocation and comminution; valgus impaction, quality of bone, open or compound fracture and age of the patient. General anaesthesia was used in all the patients. One of the following methods was used as treatment in all the cases.
- Closed reduction and percutaneous K-wires fixation.

- $\quad$ Open reduction and Internal fixation with K -wire.

- Open reduction and internal fixation with ethibond sutures.

- $\quad$ Open reduction and internal fixation with locking compression plates.

- Closed reduction and internal fixation by Intramedullary nail.

- Shoulder hemiarthroplasty.

\section{Postoperative care and follow-up}

The operated limb was immobilized in arm pouch and mobilization was started in 2nd week with shoulder wheel exercises as per patient's tolerance. Post-operative radiological evaluation was done to assess reduction and stability of fixation. Gentle passive forward flexion and internal and external rotation exercises by end of 3rd week and active exercises by 4 th to 6 th week were done. Patients were followed on OPD basis at the end of 6 weeks to one year and full functional evaluation with range of movements and function was assessed and recorded. Results were evaluated for each case based on Neer's shoulder score based on pain, function, range of motion and anatomy. The maximum points are 100 and on overall score the patient's outcome was grouped as excellent $>89$ units; satisfactory 80-89 units; unsatisfactory 70-79 units and failure $<70$ units.

The data was analysed using microsoft excel and presented in number and percentages.

\section{RESULTS}

In the present study conducted at a tertiary care hospital for two years a total of 30 cases who fulfilled the inclusion criteria were enrolled. $46.7 \%$ of the cases were between 41-60 years with $33.3 \%$ between $<18-40$ years and $20 \%$ of cases $>60$ years of age. The age range was from 19 to 68 years with a mean age of 48.2 years. Male to female sex ratio in the study was $7: 8.53 .3 \%$ of cases were females and $46.7 \%$ were males. $63.3 \%$ of the cases sustained fracture on the left side and $36.7 \%$ on right side. $83.3 \%$ of fractures were of closed type and $16.7 \%$ were open. As per Neer's type of fracture classification, the most common type of fracture observed in our study cases was two-part fracture accounting to $40 \%$ of cases followed in order by three part $(26.7 \%)$, four part observed in $23.3 \%$ of cases. Three cases $(10 \%)$ had fracture dislocation. Road traffic injury was the most common mechanism for injury in $60 \%$ of cases and next was a history of fall in $33.3 \%$ of cases and one case was electric shock and other was hit by an iron rod (Table 1).

\section{Mode of internal fixation}

Fourteen cases $(46.7 \%)$ were managed by open reduction and internal fixation with locking compression plate using 
$4.5 \mathrm{~mm}$ cortical screw plates and $6.5 \mathrm{~mm}$ cancellous screws. Percutaneous pinning was done in six cases (20\%); shoulder hemiarthroplasty in one case and open reduction internal fixation (ORIF) with ethibond suture in one case. Open reduction with $\mathrm{K}$-wire was done in four cases $(13.3 \%)$ and open reduction with $\mathrm{K}$-wire and cancellous screws in two cases $(6.7 \%)$. Closed reduction with intramedullary nailing was done in two cases $(6.7 \%)$ (Table 2). Post operatively all the cases were immobilized in arm pouch and were encouraged pendulum exercises in the second week.

Table 3 summarizes the duration of clinical and radiological union among the operated cases in the study. Clinical union was observed in $50 \%$ of cases by 12 weeks and the average time taken was 13.8 weeks. $73.3 \%$ of cases (22/30) developed radiological union between 16-18 weeks and the average time was 17.95 weeks.

Table 1: Demographic data among the cases in the study.

\begin{tabular}{|c|c|c|}
\hline Distribution of cases & $\mathbf{N}$ & $\%$ \\
\hline \multicolumn{3}{|l|}{ Age wise (years) } \\
\hline$\leq 18-40$ & 10 & 33.3 \\
\hline $41-60$ & 14 & 46.7 \\
\hline$>61$ & 6 & 20 \\
\hline \multicolumn{3}{|l|}{ Gender } \\
\hline Male & 14 & 46.7 \\
\hline Female & 16 & 53.3 \\
\hline \multicolumn{3}{|l|}{ Side of fracture } \\
\hline Right & 11 & 36.7 \\
\hline Left & 19 & 63.3 \\
\hline \multicolumn{3}{|l|}{ Type of fracture } \\
\hline Closed & 25 & 83.3 \\
\hline Open & 5 & 16.7 \\
\hline \multicolumn{3}{|l|}{ Neers's type of fracture } \\
\hline 2 part & 12 & 40 \\
\hline 3 part & 8 & 26.7 \\
\hline 4 part & 7 & 23.3 \\
\hline Fracture with dislocation & 3 & 10 \\
\hline \multicolumn{3}{|l|}{ Cause of injury } \\
\hline Road traffic accident & 18 & 60 \\
\hline Fall & 10 & 33.3 \\
\hline Others & 2 & 6.7 \\
\hline
\end{tabular}

Table 2: Distribution of surgical management among the cases in the study.

\begin{tabular}{|lll|}
\hline Surgical treatment & N & $\%$ \\
\hline ORIF with LCP & 14 & 46.7 \\
\hline ORIF with K-wire & 4 & 13.3 \\
\hline $\begin{array}{l}\text { ORIF with K-wire and } \\
\text { cancellous screws }\end{array}$ & 2 & 6.7 \\
\hline Percutaneous pinning & 6 & 20 \\
\hline Shoulder hemiarthroplasty & 1 & 3.3 \\
\hline $\begin{array}{l}\text { CRIF with intramedullary } \\
\text { nailing }\end{array}$ & 2 & 6.7 \\
\hline ORIF with ethibond suture & 1 & 3.3 \\
\hline
\end{tabular}

Table 3: Distribution of clinical and radiological union among the cases in the study.

\begin{tabular}{|lll|}
\hline Distribution of cases & $\mathbf{N}$ & $\%$ \\
\hline Clinical union (in weeks) & & \\
\hline 11 & 1 & 3.3 \\
\hline 12 & 15 & 50 \\
\hline 13 & 4 & 13.3 \\
\hline 14 & 7 & 23.3 \\
\hline 15 & 3 & 10 \\
\hline Radiological union (in weeks) & & \\
\hline $16-18$ & 22 & 73.3 \\
\hline $19-20$ & 6 & 20 \\
\hline$>20$ & 2 & 6.7 \\
\hline
\end{tabular}

\section{Neer's score study and outcome}

In the present study, Neer's score was done on patient every 1 st week, 4th week, 8 th week and finally at 14 th week. All the cases $(30 / 30)$ had score $<70$ during $1^{\text {st }}$ week, 22 cases $(73.3 \%)$ in 4 th week, 4 cases $(13.3 \%)$ in 8 th week and 1 case $(3.3 \%)$ in 14th final week which is considered as a failure outcome in our study as per Neer's criteria. In 4th week, 8 cases $(26.7 \%)$ had score between $70-79,3$ cases $(10 \%)$ in 8 th week and only 2 cases $(6.7 \%)$ in final 14 th week which is considered as unsatisfactory outcome. 80-89 score was observed in 22 cases $973.3 \%$ ) in $8^{\text {th }}$ week and 4 cases $(13.3 \%)$ in 14 th week which is considered as satisfactory outcome. $>90 \%$ score was observed in one case $(3.3 \%)$ in $8^{\text {th }}$ week and 23 cases $(76.7 \%)$ at the final 14 th week which is considered as an excellent outcome in the study. (Table 4).

Table 4: Distribution of Neer's score of cases and result in the study $(n=30)$.

\begin{tabular}{|llllll|}
\hline Neer's score & 1st week $(\%)$ & 4th week $(\%)$ & 8th week $(\%)$ & Final $(\%)$ & Result \\
\hline$<70$ & $30(100)$ & $22(73.3)$ & $4(13.3)$ & $1(3.3)$ & Failure \\
\hline $\mathbf{7 0 - 7 9}$ & 0 & $8(26.7)$ & $3(10)$ & $2(6.7)$ & Unsatisfactory \\
\hline $\mathbf{8 0 - 8 9}$ & 0 & 0 & $22(73.3)$ & $4(13.3)$ & Satisfactory \\
\hline $\mathbf{9 0}$ & 0 & 0 & $1(3.3)$ & $23(76.7)$ & Excellent \\
\hline
\end{tabular}


During the period of entire follow up, only 12 cases (40\%) developed post-operative infection and stiffness was observed in 6 cases (20\%). No other serious complications were noted in the study cases throughout the follow up period.

\section{Final outcome by Neer's score}

At the end of clinical and radiological union and full functional recovery the results were evaluated. Of the total 30 cases in the study, 23 cases had excellent results, 4 cases were satisfactory, 2 cases were unsatisfactory, and one case had a failure. The mean scores observed on Neer's score was pain (33.5 units), function (23.5 units), range of motion (16.55 units) and anatomy (6.9 units) (Table 5).

Table 5: Average score of pain, function, ROM and anatomy of cases in the study.

\begin{tabular}{|lllll|}
\hline Modalities & Min-max & Mean & Median & SD \\
\hline Pain & $29-35$ & 33.5 & 35 & 1.65 \\
\hline Function & $12-30$ & 23.5 & 24 & 3.5 \\
\hline $\begin{array}{l}\text { Range of } \\
\text { Motion }\end{array}$ & $14-19$ & 16.55 & 16 & 1.85 \\
\hline Anatomy & $4-10$ & 6.9 & 8 & 1.68 \\
\hline Total & $59-90$ & 79.65 & 82 & 7.65 \\
\hline
\end{tabular}

\section{DISCUSSION}

Management of proximal humerus fractures is a challenging task and the choice of surgical management is always a controversy. Literature and various studies describe different modalities of management, operative and non-operative techniques with different functional outcomes and complications. Age is a crucial factor in outcome where in young adults' results are uniformly good and in elderly often poor. Our study has focussed on outcome of fractures irrespective of age and type of surgical modality used in management of proximal humerus fracture based on Neer's classification of fracture and Neer's score of outcomes.

The average age incidence and range was from 19 to 68 years with a mean of 48.2 years which was similar to the finding in the study of Launonen et al with 52.65 years. ${ }^{5}$ Court-Brown et al reported in their epidemiological study with an average of 66 years, for men 56 and women 70 years. ${ }^{1,6}$ Females were more numbered than males in our study indicating more elderly females with osteoporosis as a risk factor. Similar reports were observed in the studies of Nwachukwu et al with male to female sex ratio of $8: 12{ }^{7}$ The risk of fracture increases linearly with age in females due to lack of post-menopausal treatment and awareness. The most common mode of injury in our study was road traffic injury indicating high velocity injury as main mechanism of fracture. This finding of our study was consistent to many studies in the literature which also revealed other mechanisms like electric shock, assault by a rod as other mechanisms of injury. In our study, fracture was more common on left side $(63.3 \%)$ than right $(36.7 \%)$ which is similar to finding of Gerber et al and contrary to the findings of Björkenheim et al. ${ }^{8,9}$ The study of the type of the fracture in our study found 2 part type as the most common with $40 \%$ which is similar to the findings in the study of Vijayvargiya et al and in some of the studies 3 and 4 part fractures were more common than 2 part fractures. ${ }^{10}$

In the present study 21 cases of 30 were fixed by internal fixation either by K-wires or by intramedullary nails or cancellous screws. Many authors in published literature mentioned that stable fixation and good reduction is mandatory in management of displaced fractures. In postoperative period, $40 \%$ of cases developed postoperative infection which subsided after antibiotic therapy without any sequale. Six cases developed stiffness which is due to elderly patients who were unwilling to undergo rehabilitation completely. In cases with stiffness phase wise physiotherapy was started after clinical union and satisfactory results were obtained. Similar findings were reported in the study of Doshi et al who also observed few cases of avascular necrosis postoperatively in his study. ${ }^{11}$

In our present study at the end, of total 30 cases participated 23 cases had excellent results, 4 cases were satisfactory, 2 cases were unsatisfactory, and one case was a failure. Different studies using Neer's scoring system in final outcome also reported similar pattern of results with $70-80 \%$ patient shaving excellent to satisfactory results and rest $20-30 \%$ with unsatisfactory and failure result. In our study 21 cases were managed by ORIF and 16 had excellent, 3 were satisfactory and 2 unsatisfactory. One case of failure was seen in elderly who underwent ORIF with K-wiring and failure was due to infection with the pin tract infection which was deep seated and lead to arthritis and failure. Our results with ORIF almost correlated with studies in literature but improved results are seen with minimal fixation techniques. In our study, six cases were performed percutaneous pinning with 4 excellent result, one satisfactory and one unsatisfactory. Few of the studies reveal that percutaneous pinning is far superior to ORIF regarding functional outcome. ${ }^{12,13}$

To conclude, good surgical skills, surgeons experience in selection of the type of surgery depending upon the factors like type of fracture are necessary to achieve correct and best outcome. Clinical evaluation, obtaining proper radiological views, age of the patient and activity holds the key for realistic approach and surgical management of complex humerus fractures. Proper patient selection and thorough knowledge of the anatomy and biomechanical principles are the pre-requisites for a successful surgery and good functional outcome.

Funding: No funding sources

Conflict of interest: None declared

Ethical approval: The study was approved by the institutional ethics committee 


\section{REFERENCES}

1. Court-Brown CM, Caesar B. Epidemiology of adult fractures: a review. Injury. 2006;37(8):691-7.

2. Clement ND. Management of Humeral Shaft Fractures; Non-Operative Versus Operative. Arch Trauma Res. 2015;4(2):e28013.

3. Kumar A, Waddell JP. Non-operative Management of Proximal Humerus Fractures. In: Biberthaler P, Kirchhoff C, Waddell J, eds. Fractures of the Proximal Humerus. Strategies in Fracture Treatments. Springer: Cham; 2015.

4. Carofino BC, Leopold SS. Classifications in brief: the Neer classification for proximal humerus fractures. Clin Orthop Relat Res. 2013;471(1):39-43.

5. Launonen AP, Lepola V, Saranko A, Flinkkilä T, Laitinen M, Mattila VM. Epidemiology of proximal humerus fractures. Arch Osteoporos. 2015;10:209.

6. Court-Brown CM, Garg A, McQueen MM. The epidemiology of proximal humeral fractures. Acta Orthopaedica Scandinavica. 2001;4:365-71.

7. Nwachukwu BU, Schairer WW, McCormick F, Dines DM, Craig EV, Gulotta LV. Arthroplasty for the surgical management of complex proximal humerus fractures in the elderly: A cost-utility analysis. J Shoulder Elbow Surg. 2016;25(5):704-13.

8. Gerber C, Worner CM, Vienne P. Internal fixation of complex fractures of the proximal humerus. J Bone Joint Surg (Br). 2004;86(60):848-55.
9. Björkenheim JM, Pajarinen J, Savolainen V. Internal fixation of proximal humeral fractures with locking compression plate: A retrospective evaluation of 72 patients followed for a minimum of 1 year. Acta Orthop Scand. 2004;75:741-5.

10. Vijayvargiya M, Pathak A, Gaur S. Outcome analysis of locking plate fixation in proximal humerus fracture. J Clin Diag Res. 2016;10(8):1-5.

11. Doshi C, Sharma GM, Naik LG, Badgire KS, Qureshi F. Treatment of Proximal Humerus Fractures using PHILOS Plate. J Clin Diagn Res. 2017;11(7):10-3.

12. Wijgman AJ, Roolker W, Patt TW, Raaymakers EL, Marti RK. Open reduction and internal fixation of three and four-part fractures of the proximal part of the humerus. J Bone Joint Surg Am. 2002;84:1919-25.

13. Thyagarajan DS, Haridas SJ, Jones D, Dent C, Evans R, Williams R. Functional outcome following proximal humeral interlocking system plating for displaced proximal humeral fractures. Int J Shoulder Surg. 2009;3:57-62.

Cite this article as: Study of functional outcome of surgical management of proximal humerus fracture by various modalities: a two-year study at a tertiary care hospital. Vijayanand A, Jayasomeswar N. Int J Res Orthop 2020;6:242-6. 